\author{
돈육 뒷다리 부위의 발골시간이 프레스햄의 품질 특성에 \\ 미치는 영향 \\ 양한술 · 주선태 · 박구부 \\ 경상대학교 동물자원과학부, 경상대학교 농업생명과학연구원
}

\title{
Effect of Deboning Time on Quality Characteristics of Pressed Pork Ham
}

\author{
H. S. Yang, S. T. Joo and G. B. Park \\ Department of Animal Science, Gyeongsang National University, Institute of Agriculture and Life \\ Science, Gyeongsang National University
}

\begin{abstract}
To investigate the effects of deboning time and muscle type of ham on quality characteristics of cooked press ham, a total of twelve pigs (barrow, $100 \pm 5 \mathrm{~kg}$ ) were slaughtered and split in half. The left side ham of carcasses was deboned immediately after slaughter whereas the right side ham was deboned after chilling for 24 hours at $4^{\circ} \mathrm{C}$. Each of two muscles (SM; Semimembranosus, BF; Biceps femoris) was used to make a press ham. The $\mathrm{pH}$ of hot-boning muscles was significantly $(\mathrm{p}<0.05)$ higher than that of coldboning muscles, and the $\mathrm{pH}$ of $\mathrm{SM}$ samples was significantly $(\mathrm{p}<0.05)$ higher than $\mathrm{BF}$ samples. Hot-boning muscles showed significantly $(\mathrm{p}<0.05)$ longer sarcomere length compared with cold-boning muscles. There was no significant difference in myoglobin $(\mathrm{Mb})$ percentage between $\mathrm{SM}$ and BF muscles, but SM samples of hot-boning showed significantly $(\mathrm{p}<0.05)$ lower $\mathrm{L}^{*}$ value compared to hot-boning $\mathrm{BF}$ samples. The lightness $\left(\mathrm{L}^{*}\right)$ of hot-boning muscles was significantly $(\mathrm{p}<0.05)$ lower than that of cold-boning muscles. These results suggested that the dark color of hot-boning samples might be due to not only the high muscle $\mathrm{pH}$ but also the long sarcomere length without difference in Mb percentage. Hardness and gumminess of hot-boning press ham were significantly $(\mathrm{p}<0.05)$ lower than those of cold-boning samples. These results implied that color and $\mathrm{pH}$ of press ham did not affected by deboning time or muscle type of ham. However data suggested that texture and panel test of press ham might be improved by using hot-boned muscle due to long sarcomere length of raw meat.
\end{abstract}

(Key words : Deboning time, Meat type, Press ham, Texture property)

$$
\text { I. 서 론 }
$$

식육의 품질은 소비자의 기호성에 따라 평가
되며, 신선육과 가공육에 따라 다르다. 가축의 유전적 혈통과 원료육 및 지방의 품질이 최종 산물의 관능적 및 기술적으로 품질을 판단하는

Corresponding author: Gu Boo Park, Department of Animal Science, College of Agriculture and Life Science, Gyeongsang National University, 900 Gajwa-dong, Jinju, Gyeongnam 660-701, Korea. Tel : 82-55-751-5515, Fax : 82-55-756-7171, E-mail : gbpark@gnu.ac.kr 
데 중요한 요인으로 작용한다(Arnau, 1991; Guerrero 등, 1996). 육의 특성인 육색, 보수력, 가열감량 및 조직감은 사후 $\mathrm{pH}$ 감소에 의한 생화학적 변화에 영향을 받으며(van der Wal 등, 1997), 사후 온도와 저장 시간은 근육의 조 직적 특성에 영향을 미치는 중요한 요인으로 작용한다(Van Moeseke와 De Smet, 1999).

우리나라 돼지 도체 가공 방법에는 일반적으 로 냉도체 발골(cold boning)과 온도체 발골(hot boning)이 널리 이용되어 왔다. 최근에 많이 이 용되고 있는 온도체 발골은 냉도체 발골에 비 해 에너지 비용을 줄일 수 있고 가공 수율을 높일 수 있는 장점이 있으며(Anonymous, 1980; Cross와 Seidman, 1985), 식육을 사후강직 전에 처리함으로써 높은 사후 $\mathrm{pH}$ 를 유지하여 식육 의 보수력이 증진되는 것과 같이 경제적인 이 익을 얻을 수 있다(Farouk와 Swan, 1999). 또한 육가공 원료육으로서의 기능적 특성인 보수력, 유화력, 염용성 단백질의 추출성 및 결착력 등 을 증가시켜 제품의 수율과 품질이 향상된다 (Banwart, 1979). 온도체 발골육의 근육 온도는 보수력 및 식육의 사후 도체처리에 주요한 요 인으로 작용한다는 보고(Honikel과 Reagan, 1986)와 같이 사후 도체 온도가 $10 \sim 15^{\circ} \mathrm{C}$ 일 때 연도가 향상되며, 그 이하 또는 이상의 온도에 서는 냉각과 가열에 의해 연도가 감소된다 (Nuss와 Wolfe, 1980). 즉, 온도체 발골을 하여 온도를 $10^{\circ} \mathrm{C}$ 이하로 급속히 냉각시키면 육즙삼 출은 증가하지만, 온도체 발골육을 천천히 냉 각시키면 냉도체 발골육과 육즙삼출 면에서 비 교할 때 유의적인 차이가 없는 것으로 알려지 고 있다.

그러나 온도체 발골육의 높은 근육온도는 식 육표면의 호기성 미생물의 급속한 성장에 따라 식육이 빨리 부패되고 불쾌취가 발생하며 (Banwart, 1979), 급냉으로 인한 근절의 단축 (Debvine 등, 1999; Ress 등, 2002)으로 연도가 감소되는 등 단점을 가지므로, 강직전 - 후 근육 을 이용한 제조 공정상의 차이뿐만 아니라, 원
료육의 사후 처리시간에 따른 육가공 제품 특 성 차이를 확인하였다(Ockerman과 $\mathrm{Wu}, 1990)$. 또한 온도체 발골육과 냉도체 발골육간의 처리 시간과 사후 도체 냉각속도의 차이에 따라 품 질 차이가 발생될 수 있으므로 국내에서 관행 적으로 시행되고 있는 온도체 발골과 냉도체 발골의 방법적 차이가 돈육 및 육제품의 품질 특성에 미치는 영향에 대해 알아보고자 발골시 간을 달리한 돈육 뒷다리 부위의 대표적인 근 육을 이용한 프레스햄의 품질 특성을 비교하였 다.

\section{ㅍ. 재료 및 방법}

\section{1. 공시재료 및 시험구 설정}

사양조건이 동일한 거세돈 12 두를 상업적 방 법으로 도축한 후, 사후 1 시간 이내의 도체를 이용하여 좌도체는 온도체(심부온도 $35^{\circ} \mathrm{C}$ ) 상태 에서 뒷다리 부위를 분리, 발골 후 24시간 냉 각시켰으며, 우도체는 뒷다리 부위를 24시간 냉각 후 냉도체(심부온도 $4^{\circ} \mathrm{C}$ ) 상태에서 발골하 여, 돼지 뒷다리 부위 중 주요 2개 근육(SM; Semimembranosus, BF; Biceps femoris)을 각각 분 할, 채취하였다. 이렇게 채취된 근육은 $\mathrm{pH}$, 근 절길이, 표면육색(CIE L*a*b*), 육색소( $\mathrm{Mb}$; myoglobin) 함량을 측정한 다음(사후 24 시간 째), grinder를 이용하여 직경 $5 \mathrm{~mm}$ plate에서 분쇄시켜, $4^{\circ} \mathrm{C}$ 냉장실에서 48 시간 염지시켰다. 이 때 염지 조건은 발골시간에 따라 동일하게 $72 \%$ 의 돈육 (SM 또는 $\mathrm{BF}), 10 \%$ 돈지방, $10 \%$ 물, $4 \%$ 전분, $1.7 \%$ Regal brine mix, $0.2 \%$ phosphate, $0.3 \%$ nucleo- tide, $1.3 \%$ 소금 및 $0.5 \%$ 설탕을 이용하였다. 염지된 분쇄육은 직 경 $30 \mathrm{~mm}$ 의 충진기 (H15, TALSA, Spain)를 사 용하여 파이브로스 케이싱 $(\varnothing 3.6 \times 15 \mathrm{~cm})$ 에 충전 한 후 steam chamber (SAA10, Steammaster, Germany)를 이용하여 중심온도 $75{ }^{\circ} \mathrm{C}$ 에서 30 분 동안 가열하였다. 가열이 끝난 샘플은 $4^{\circ} \mathrm{C}$ 냉 
장고에서 24시간 냉각 후 본 연구를 위한 공시 재료로 햄의 색깔, $\mathrm{pH}$, 조직감 및 관능평가를 분석하였다.

\section{2. 조사항목}

육색(CIE value)은 Color-meter(CR-310, Milolta, Japan)를 이용하여 명도(lightness) 및 적색도 (redness)값을 측정하였다. 이때 표준화 작업은 표준색판 No 12633117을 이용하여 $\mathrm{Y}=93.5, \mathrm{x}$ $=0.3132, \mathrm{y}=0.3198$ 값으로 표준화시킨 후 육색 을 측정하였다.

$\mathrm{pH}$ 측정은 시료 $3 \mathrm{~g}$ 을 채취하여 증류수 27 $\mathrm{mL}$ 와 함께 homogenizer(IKT, T25-B, Malaysia) 로 $14,000 \mathrm{rpm}$ 에서 균질시킨 후 $\mathrm{pH}$-meter (MP230, Mettler, Switzerland)로 측정하였다.

육색소인 마이오글로빈 $(\mathrm{Mb})$ 의 함량 측정은, 분쇄 돈육을 $2 \mathrm{~g}$ 취하여 냉장고에 보관중인 phosphate buffer ( $\mathrm{pH}$ 6.8, ironic strength 0.04)를 $10 \mathrm{ml}$ 넣은 후 $13,000 \mathrm{rpm}$ 에서 10 초간 균질화 시켰다. 이 때 $\mathrm{Mb}$ 추출은 Wariss(1979)의 방법 으로 추출하였고, 균질액을 냉암소에서 1시간 방치한 후 $5,000 \mathrm{~g}$ 에서 30 분간 원심분리하였다. 상층액을 Whatman No. 3 여과지로 여과한 후 추출한 상층액 $1 \mathrm{ml}$ 에 potassium ferricyanid (0.6 $\mathrm{mM}) 100 \mu \mathrm{l}$ 과 potassium cyanid $(0.8 \mathrm{mM}) 900$ $\mu \ell$ 을 넣은 뒤 $540 \mathrm{~nm}$ 에서 측정하였다.

$$
\begin{aligned}
M b .(\mathrm{mg} / \mathrm{g}) & =\frac{\text { O.D. }}{11300} \times \\
& \frac{17000 \times 0.25 \times 1000}{\text { Sample }(\mathrm{g})}
\end{aligned}
$$

$* \mathrm{OD}=\mathrm{A} 540 \mathrm{~nm}-700 \mathrm{~nm}$

근절길이는 Cross 등(1980)의 방법에 따라 시 료를 일정한 크기 $(3 \times 3 \mathrm{~cm})$ 로 자르고 solution A 에서 2시간 방치한 후 solution $\mathrm{B}$ 에서 17-19 시 간 방치한 다음 균질 시킨 후 근절길이를 측정 하였다.
Sarcomere length $(\mu \mathrm{m})=$

$$
\frac{632.8 \times 10^{3} \times \mathrm{D} \times \sqrt{(\mathrm{T} / \mathrm{D})^{2}+1}}{\mathrm{~T}}
$$

조직감 측정은 분석전 가열된 프레스햄은 상 온에서 1 시간 방치 후 조직감 측정을 위하여 직경 $3 \mathrm{~cm}$, 높이 $2 \mathrm{~cm}$ 크기로 잘라 Instron (Model 3343, England)을 이용하여 1회 측정시 $70 \%$ 침투력 및 2회 반복의 조건으로 경도 (Hardness), 응집성(cohesiveness), 탄력성(springiness) 및 검성(gumminess) 값을 측정하였다. 조 직감 측정은 각 각 처리구마다 10 회 반복 측정 하였으며, 이때 기기 조건은 road speed: 200 $\mathrm{mm} / \mathrm{min}$, road cell : $10 \mathrm{~kg}$ 이었다.

관능평가는 잘 훈련된 요원 8 명을 선발하여 프레스햄의 향, 다즙성, 연도 및 전체적인 기호 도를 9점 척도법으로 조사하였다. “1”에 가까울 수록 싫어함, “9”에 가까울수록 좋아함으로 표 현하였다.

\section{3. 통계분석}

실험에서 얻어진 성적은 SAS/PC (1997)의 General Linear Model Procedure를 이용하여 분 석하였으며, 처리구에 따른 비교는 Duncan의 다중검정을 실시하였다.

\section{III. 결과 및 고찰}

\section{1. 발골시간에 따른 뒷다리 부위 주요 근육 의 품질 특성}

뒷다리 부위 주요 근육의 육색 측정 결과 (Table 1), 명도( $\left.\mathrm{L}^{*}\right)$ 는 온도체 발골육이 냉도체 발골육에 비해 유의적으로 $(\mathrm{p}<0.05)$ 낮은 값을 나타내었고, 온도체 발골육 중 $\mathrm{SM}$ 이 $\mathrm{BF}$ 에 비 해 유의적인 $(\mathrm{p}<0.05)$ 낮은 명도 값을 보였다. 또한 적색도 $\left(\mathrm{a}^{*}\right)$ 는 같은 처리구내 두 근육간의 
Table 1. Effects of deboning time on raw meat color $\left(L^{*} a^{*} b^{*}\right)$ of pork

\begin{tabular}{|c|c|c|c|c|}
\hline \multicolumn{2}{|c|}{ Treatments $^{1)}$} & Lightness $\left(\mathrm{L}^{*}\right)$ & Redness (a*) & Yellowness (b*) \\
\hline \multirow{2}{*}{ Hot-boning } & $\mathrm{SM}$ & $46.14 \pm 1.70^{\mathrm{C}}$ & $11.38 \pm 2.01^{\mathrm{A}}$ & $4.29 \pm 0.47$ \\
\hline & $\mathrm{BF}$ & $50.50 \pm 1.65^{\mathrm{B}}$ & $10.55 \pm 1.76^{\mathrm{AB}}$ & $4.97 \pm 1.15$ \\
\hline \multirow{2}{*}{ Cold-boning } & $\mathrm{SM}$ & $51.71 \pm 1.62^{\mathrm{AB}}$ & $9.55 \pm 2.46^{\mathrm{B}}$ & $4.38 \pm 1.41$ \\
\hline & $\mathrm{BF}$ & $53.13 \pm 3.04^{\mathrm{A}}$ & $10.59 \pm 1.28^{\mathrm{AB}}$ & $5.12 \pm 1.26$ \\
\hline
\end{tabular}

Data are expressed as means \pm SD.

${ }^{A-C}$ Means in the same column with different superscripts are significantly different $(\mathrm{P}<0.05)$.

1) The difference of deboning time to follow hot-boning and cold-boning on those muscles in ham of pork (SM: Semimenbranosus, BF: Biceps femoris)

차이보다는 온도체 발골육의 $\mathrm{SM}$ 근육이 냉도 체 발골육의 $\mathrm{SM}$ 근육보다 유의적으로 높은 값 을 나타내었다 $(\mathrm{P}<0.05)$. 따라서 발골시간에 따 라 온도체 발골육이 냉도체 발골육에 비해 낮 은 명도 값을 나타내었는데, 이러한 요인은 사 후대사작용의 속도와 관계가 있다. 즉, 근육의 사후대사 진행속도는 온도에 영향을 크게 받으 며, 근육온도가 높을수록 ATPase를 비롯한 각 종 효소들의 작용이 빨라서 대사가 급격히 진 행되어 육질에 많은 영향을 미친다(Bendall, 1975). 또한 Kannan 등 (1998)은 도체의 사후처 리시간은 육색의 명도 및 적색도에 영향을 미 치며, 이러한 이유는 강직전 근육의 높은 산소 소비율로 인한 효소내 Metmyoglobin의 활력이 증가되기 때문이라 보고하였다. 그러나 본 연
구 결과, 사후처리시간에 따른 육색소 함량의 차이보다는 온도체 발골육의 높은 $\mathrm{pH}$ 는 육색 을 어둡게 만든 결과 명도 값이 낮게 나타난 것으로 사료된다(Table 2).

발골시간에 따른 뒷다리 부위 주요 근육의 육색소 함량, $\mathrm{pH}$ 및 근절길이 측정 결과(Table 2), 육색소 함량의 경우, 모든 처리구에서 유의 적인 차이가 나타나지 않았다. 그러나 근육의 $\mathrm{pH}$ 에서는 온도체 발골육에서 유의적으로 $(\mathrm{p}<$ $0.05)$ 높은 값을 나타내었다. 또한 근절길이는 온도체 발골육에서 유의적으로 $(\mathrm{p}<0.05)$ 높은 값 을 나타내었다. 근육의 $\mathrm{pH}$ 저하는 방혈과 동시 에 시작되어 최종 $\mathrm{pH}$ 에 도달하는데, 사후도체 온도와 $\mathrm{pH}$ 의 관계에 있어서는 사후 도체온도 가 감소할수록 $\mathrm{pH}$ 또한 감소하게 된다(Maribo

Table 2. Effects of deboning time on raw meat of myoglobin (Mb) percentage, muscle $\mathrm{pH}$ and sarcomere length of pork

\begin{tabular}{|c|c|c|c|c|}
\hline \multicolumn{2}{|c|}{ Treatments $^{1)}$} & \multirow{2}{*}{$\frac{\mathrm{Mb}(\%)}{1.99 \pm 0.42}$} & \multirow{2}{*}{$\frac{\mathrm{pH}}{5.91 \pm 0.06^{\mathrm{A}}}$} & \multirow{2}{*}{$\begin{array}{c}\text { Sarcomere length }(\mu \mathrm{m}) \\
1.71 \pm 0.09^{\mathrm{A}}\end{array}$} \\
\hline & SM & & & \\
\hline Hot-boning & $\mathrm{BF}$ & $1.96 \pm 0.62$ & $5.78 \pm 0.07^{\mathrm{AB}}$ & $1.69 \pm 0.05^{\mathrm{AB}}$ \\
\hline \multirow{2}{*}{ Cold-boning } & SM & $1.90 \pm 0.13$ & $5.67 \pm 0.05^{\mathrm{BC}}$ & $1.65 \pm 0.08^{\mathrm{BC}}$ \\
\hline & $\mathrm{BF}$ & $1.95 \pm 0.05$ & $5.63 \pm 0.09^{\mathrm{C}}$ & $1.62 \pm 0.07^{\mathrm{C}}$ \\
\hline
\end{tabular}

Data are expressed as means $\pm \mathrm{SD}$.

A-C Means in the same column with different superscripts are significantly different $(\mathrm{P}<0.05)$.

1) Treatments are the same of Table 1. 
등, 1998). 근섬유의 단축은 온도에 많은 영향 을 받으며, 사후강직 전 근육은 저장기간 동안 저장온도가 낮을수록 근절의 단축은 많이 발생 된다(Locker와 Hagyard, 1963; Olsson 등, 1994). 또한 백색근섬유의 함량이 높은 근육은 적색근 섬유의 함량이 높은 근육에 비해 단축이 지속 적으로 일어난다(Busch 등, 1972; Hertzman 등, 1993). 그러나 냉도체 발골육에 비해 온도체 발 골육에서 높은 $\mathrm{pH}$ 와 긴 근절길이를 보인 것은 저장온도의 영향보다는 발골시간에 따라 $\mathrm{pH}$ 및 근절길이가 영향을 받는 것으로 사료된다.

\section{2. 발골시간에 따른 뒷다리 부위 주요 근육을 이용하여 제조한 프레스햄의 품질 특성}

프레스햄의 색 및 $\mathrm{pH}$ 측정 결과를 Table 3에 서 나타내었다. 명도 $\left(\mathrm{L}^{*}\right)$ 에서는 발골시간 및 뒷 다리부위 주요 근육간에 유의적인 차이가 나타
나지 않았다. 이는 신선육 상태에서는 온도체 발골 및 냉도체 발골뿐만 아니라 두 주요 근육 간에 유의적인 차이가 나타났으나, 이를 가열 하여 프레스햄 제조시, 발골시간 및 근육간의 차이가 나타나지 않음을 알 수 있다. 그러나 적색도(a*)는 발골시간의 차이보다는 냉도체 발 골육의 $\mathrm{BF}$ 근육이 $\mathrm{SM}$ 근육에 비해 낮은 값을 나타내었다 $(\mathrm{P}<0.05)$. 또한 황색도 $\left(\mathrm{b}^{*}\right)$ 는 온도체 발골육의 $\mathrm{SM}$ 이 냉도체 발골육인 $\mathrm{SM}$ 및 $\mathrm{BF}$ 근 육을 이용해 제조된 프레스햄에 비해 유의적으 로 높은 값을 나타내었다 $(\mathrm{P}<0.05)$. 프레스햄의 $\mathrm{pH}$ 의 경우, 모든 처리구간에 유의적인 차이를 나타내지 않았다.

프레스햄의 조직감 측정 결과(Table 4), 경도 (물질을 변형시킬 때 필요한 힘)는 온도체 발골 육에 비해 냉도체 발골육에서 유의적으로 높게 나타났다 $(\mathrm{P}<0.05)$. 그러나 온도체 발골육에서 높은 탄력성을 보여 물체를 외부로부터 힘을

Table 3. Effects of deboning time on color $\left(L^{*} a^{*} b^{*}\right)$ and $\mathrm{pH}$ of press ham

\begin{tabular}{lccccc}
\hline \multicolumn{2}{c}{ Treatments $^{1)}$} & Lightness $\left(\mathrm{L}^{*}\right)$ & Redness $\left(\mathrm{a}^{*}\right)$ & Yellowness $\left(\mathrm{b}^{*}\right)$ & $\mathrm{pH}$ \\
\hline \multirow{2}{*}{ Hot-boning } & $\mathrm{SM}$ & $66.45 \pm 2.65$ & $11.59 \pm 1.21^{\mathrm{A}}$ & $8.53 \pm 0.76^{\mathrm{A}}$ & $6.23 \pm 0.11$ \\
& $\mathrm{BF}$ & $67.01 \pm 1.37$ & $11.41 \pm 0.49^{\mathrm{A}}$ & $8.04 \pm 0.67^{\mathrm{AB}}$ & $6.14 \pm 0.10$ \\
\hline \multirow{2}{*}{ Cold-boning } & $\mathrm{SM}$ & $67.18 \pm 1.80$ & $11.88 \pm 0.85^{\mathrm{A}}$ & $7.42 \pm 0.25^{\mathrm{B}}$ & $6.24 \pm 0.10$ \\
& $\mathrm{BF}$ & $68.39 \pm 1.15$ & $10.43 \pm 0.47^{\mathrm{B}}$ & $7.04 \pm 0.43^{\mathrm{B}}$ & $6.21 \pm 0.09$ \\
\hline
\end{tabular}

Data are expressed as means \pm SD.

A-B Means in the same column with different superscripts are significantly different $(\mathrm{P}<0.05)$.

1) Treatments are the same of Table 1.

Table 4. Effects of deboning time on texture analysis of press ham

\begin{tabular}{lccccc}
\hline \multicolumn{2}{c}{ Treatments $^{1)}$} & Hardness (kg) & Cohesiveness (\%) & Springiness (mm) & Gumminess (kg) \\
\hline \hline \multirow{2}{*}{ Hot-boning } & SM & $0.53 \pm 0.04^{\mathrm{B}}$ & $37.51 \pm 9.23$ & $16.36 \pm 4.55^{\mathrm{A}}$ & $92.27 \pm 20.70^{\mathrm{C}}$ \\
& BF & $0.56 \pm 0.05^{\mathrm{B}}$ & $41.05 \pm 14.46$ & $12.18 \pm 3.39^{\mathrm{AB}}$ & $148.76 \pm 49.07^{\mathrm{BC}}$ \\
\hline \multirow{2}{*}{ Cold-boning } & SM & $0.79 \pm 0.05^{\mathrm{A}}$ & $52.08 \pm 6.08$ & $12.45 \pm 2.63^{\mathrm{AB}}$ & $255.66 \pm 32.97^{\mathrm{AB}}$ \\
& BF & $0.85 \pm 0.06^{\mathrm{A}}$ & $64.57 \pm 9.21$ & $7.92 \pm 1.19^{\mathrm{B}}$ & $307.23 \pm 36.32^{\mathrm{A}}$ \\
\hline
\end{tabular}

Data are expressed as means \pm SD.

A-C Means in the same column with different superscripts are significantly different $(\mathrm{P}<0.05)$.

1) Treatments are the same of Table 1. 
Table 5. Effects of deboning time on sensory evaluation of press ham

\begin{tabular}{lccccc}
\hline \multicolumn{2}{c}{ Treatments $^{1)}$} & Aroma & Juiciness & Tenderness & Overall acceptability \\
\hline \multirow{2}{*}{ Hot-boning } & SM & $6.25 \pm 0.46^{\mathrm{A}}$ & $6.20 \pm 0.77^{\mathrm{A}}$ & $5.88 \pm 1.36$ & $6.50 \pm 0.76^{\mathrm{A}}$ \\
& $\mathrm{BF}$ & $5.63 \pm 0.52^{\mathrm{AB}}$ & $5.25 \pm 0.71^{\mathrm{B}}$ & $5.25 \pm 0.89$ & $5.63 \pm 0.74^{\mathrm{B}}$ \\
\hline \multirow{2}{*}{ Cold-boning } & $\mathrm{SM}$ & $5.13 \pm 1.13^{\mathrm{B}}$ & $5.60 \pm 0.74^{\mathrm{AB}}$ & $5.47 \pm 0.74$ & $5.80 \pm 0.77^{\mathrm{AB}}$ \\
& $\mathrm{BF}$ & $4.73 \pm 1.22^{\mathrm{B}}$ & $6.00 \pm 1.07^{\mathrm{AB}}$ & $5.80 \pm 0.86$ & $5.33 \pm 0.98^{\mathrm{B}}$ \\
\hline
\end{tabular}

Data are expressed as means \pm SD.

${ }^{A-B}$ Means in the same column with different superscripts are significantly different $(\mathrm{P}<0.05)$.

1) Treatments are the same of Table 1 .

가한 후 생긴 변형이 힘을 제거시 원상 복귀하 는 힘이 뛰어난 것으로 나타났다 $(\mathrm{P}<0.05)$. Locker(1960)는 근육의 단축 정도에 따라 식육 의 저작감에 영향을 미치며, Marsh와 Leet (1966)는 근육의 단축이 감소하는 것은 전단력 이 감소하는 것과 관련이 있다고 보고하였다. 또한 Koohmaraie 등(1995)은 연도에 영향을 미 치는 것은 강직온도와 효소작용의 정도에 따라 변이가 심하다고 하였다. 따라서 본 실험에서 는 온도체 발골육이 냉도체 발골육에 비해 낮 은 경도 및 높은 탄력성을 보인 것은 강직 전 근육인 온도체 발골육에서 긴 근절길이로 인해 이를 가공한 프레스햄에서 낮은 경도 및 높은 탄력성을 나타낸 것으로 사료된다.

프레스햄의 관능평가 결과(Table 5), 향, 다즙 성 및 전체적인 기호도에서 유의적인 차이를 나타내었다 $(\mathrm{P}<0.05)$. 향에서 온도체 발골육에서 냉도체 발골육에 비해 높은 점수를 획득하였으 며, 다즙성은 발골시간에 따른 차이보다는 온 도체 발골육의 $\mathrm{SM}$ 근육이 $\mathrm{BF}$ 보다 높은 선호 도를 보여준다. 또한 전체적인 기호도에서 발 골시간에 따른 차이보다는 온도체 발골 및 냉 도체 발골육의 $\mathrm{SM}$ 근육을 이용하여 제조된 프 레스햄이 $\mathrm{BF}$ 근육보다 높은 기호도를 보여준 다.

\section{IV. 요 약}

돼지 뒷다리 부위의 발골시간이 프레스햄의 품질에 미치는 영향을 알아보고자, 본 실험을 실시하였다. 그 결과, 원료육의 $\mathrm{pH}$ 는 두 근육 모두 온도체 발골육이 유의적으로 $(\mathrm{p}<0.05)$ 높았 으며, 온도체 발골육 중 $\mathrm{SM}$ 이 $\mathrm{BF}$ 보다 유의적 으로 $(\mathrm{p}<0.05)$ 높은 $\mathrm{pH}$ 값을 보였다. 표면 육색 의 경우 온도체 발골육의 명도 $\left(\mathrm{L}^{*}\right)$ 값이 냉도 체 발골육보다 유의적으로 $(\mathrm{p}<0.05)$ 낮게 나타났 으며, 온도체 발골육 중 $\mathrm{SM}$ 이 $\mathrm{BF}$ 보다 유의적 으로 $(\mathrm{p}<0.05)$ 낮은 명도 값을 나타내었다. 또한 온도체 발골육의 근절길이는 냉도체 발골육보 다 긴 것으로 나타났다 $(\mathrm{p}<0.05)$. 제품의 색 및 $\mathrm{pH}$ 는 유의적인 차이를 보이지 않았지만, 온도 체 발골육으로 제조한 프레스햄의 경도에서 냉 도체보다 유의적으로 $(\mathrm{p}<0.05)$ 낮게 나타났다. 또한 전체적인 기호도에서 발골시간에 따른 차 이보다는 온도체 발골 및 냉도체 발골육의 SM 근육을 이용하여 제조된 프레스햄이 $\mathrm{BF}$ 근육 보다 높은 기호도를 나타내었다.

\section{$\mathrm{V}$. 인 용 문 헌}

1. Anoymous. 1980. Hot processing, economic feasibility of hot processing of carcasses. Bull. 
639 Agricultural Experiment Station, Kansas State Univ. Manhattan. Dec.

2. Arnau, J., Gou, P. and Guerrero, L. 1991. The effects of freezing, meat $\mathrm{pH}$ and storage temperatures on the formation of white film and tyrosine crystals in dry-cured hams. J. Sci. Food Agric. 66:279-282.

3. Banwart, G. 1979. Basic food microbiology. Westport, Connecticut: AVI Publishing Company Incorporated. 22-84.

4. Busch, W. A., Goll, D. E. and Parrish, F. C. J. 1972. Molecular properties of postmortem muscle. Isometric tension development and decline in bovine, porcine and rabbit muscle. J. Food Sci. 37:289-299.

5. Cross, H. R. and Seideman, S. C. 1985. Use of electrical stimulation for hot boning of meat. In A. M. Pearson and T. R. Dutson (Eds.), Advances in meat research. Electrical stimulation Vol. 1. Connecticut:AVI Publishing Co Inc.

6. Cross, R. W., Weat, R. L. and Dutson, T. R. 1980. Comparison of methods for measuring sarcomere length in beef semitendinosus muscle. Meat Sci. 5:261-266.

7. Debvine, C. E., Wahlgren, N. M. and Tongberg, E. 1999. Effect of rigor temperature on muscle shortening and tenderization of restrained and unrestrained beef $M$. longissmus thiracicus et lumborum. Meat Sci. 51:61-72.

8. Farouk, M. M. and Swan, J. E. 1999. Effect of rigor temperature and frozen storage on functional properties of hot-boned manufacturing beef. Meat Sci. 49:233-247.

9. Guerrero, L., Gou, P. and Arnau, J. 1996. Study of the physicochemical and characteristics of drycured hams in three pig genetic types. J. Sci Food Agric. 70:526-530.

10. Hertzman, C., Olssen, U. and Tornberg, E. 1993. The influence of high temperature, type of muscle and electrical stimulation on the course of rigor, ageing and tenderness of beef muscles. Meat Sci. 35:119-141.

11. Honikel, K. O. and Reagan, J. O. 1986. Influence of different chilling conditions on hot-boned pork. J. Food Sci. 51:766-768.

12. Kannan, G., Heath, J. L., Wabeck, C. J., Owens, S. L. and Mence, J. A. 1998. Elevated plasma corticosterone concentrations influence the onset of rigor mortis and meat color in broilers. Poultry Sci. 77:322-328.

13. Koohmaraie, M., Killefer, J., Bishop, M. D., Shackelford, S. D., Wheeler, T. L. and Arbona, J. P. 1995. Calpastatin-based methods for predicting meat tenderness. In: Ouall, A., Demeyer, D. I., Smulders, F. J. M. (Eds). Expression of tissue proteinases and regulation of protein degradation as related to meat quality. ECCEAMST. III. Utrecht. The Netherlands. pp. 395-412.

14. Locker, R. H. 1960. Degree of muscular contraction as a factor in tenderness of beef. Food Res. 25:304-307.

15. Locker, R. H. and Hagyard, C. J. 1963. A cold shortening effect in beef muscles. J. Food Sci and Agric. 14:787-793.

16. Marbio, H., Olsen, E. V., Patricia, B. G., Anders, J. N. and Anders, K. 1998. Effect of early postmortem cooling on temperature, $\mathrm{pH}$ fall and meat quality in pigs. Meat Sci. 50:175-189.

17. Marsh, B. B. and Leet, N. G. 1966. Studies in meat tenderness. III. The effects of cold shortening on toughness. J. Food Sci. 31:450-459.

18. Nuss, J. I. and Wolfe, F. H. 1980. Effect of postmortem storage temperatures on isometic tension, $\mathrm{pH}$, ATP, glycogen and glucose-6-phosphate for elected bovine muscles. Meat Sci. 5: 201-213.

19. Ockerman, H. W. and Wu, Y. C. 1990. Hotboning, tumbling, salt and chopping temperature effects on cooking yield and acceptability of emulsion-type pork sausage. J. Food Science. 55:1255-1257. 
20. Olssen, U., Hertzman, C. and Tornberg, E. 1994. The influence of low temperature, type of muscle and electrical stimulation on the course of rigor, ageing and tenderness of beef muscles. Meat Sci. 37:115-131.

21. Rees, M. P., Trout, G. P. and Warner, R. D. 2002. Tenderness of pork $\mathrm{m}$. longissimus thoracis et lumborum after accelerated boning. Part I . Effect of temperature conditioning. Meat Sci. 61:205-214.

22. SAS. 1997. SAS/STAT Software for PC. SAS Institude Inc., Cary, NC, USA.
23. Van der Wal, P. G., Engel, B. and Hulsegge, B. 1997. Causes for variation in pork quality. Meat Sci. 46:319-327.

24. Van Moeseka, W. and De Smet, S. 1999. Effect of time of deboning and sample size on drip loss of pork. Meat Sci. 52:151-156.

25. Warriss, P. D. 1979. The extraction of heam pigments from fresh meat. J. Food Technol. 14: 5-80.

(접수일자 : 2007. 3. 7. / 채택일자 : 2007. 6. 19.) 